\title{
A AGRICULTURA ORGÂNICA NO BRASIL: UM PERFIL A PARTIR DO CENSO AGROPECUÁRIO 2006
}

\author{
Andréia Vigolo Lourenço ${ }^{1}$ \\ Sergio Schneider ${ }^{2}$ \\ Marcio Gazolla ${ }^{3}$
}

\section{RESUMO}

Este artigo tem como objetivo analisar o perfil da produção orgânica brasileira a partir dos dados do Censo Agropecuário 2006, o último disponível. O trabalho identifica e quantifica os estabelecimentos que produziram orgânicos através do mapeamento da produção e dos produtores, suas características socioeconômicas e as macrorregiões em que se situam. A metodologia utilizada consistiu na análise de dados secundários do Censo Agropecuário 2006 do IBGE, retirados do website SIDRA, a partir da variável 'uso de agricultura orgânica'. Os resultados mostram que a agricultura orgânica ainda é pouco expressiva no Brasil. No que se refere ao perfil socioeconômico, os estabelecimentos que fazem uso da agricultura orgânica são de agricultores familiares, especialmente os classificados no Grupo B do PRONAF (que são os mais pobres), que participam em cooperativas ou entidades de classe. Estes agricultores são, em sua maioria, proprietários das terras, apresentam baixo grau de escolarização com pouco ou nenhum acesso à assistência técnica. As atividades econômicas mais frequentes onde os orgânicos são encontrados são a pecuária e as lavouras temporárias. Trata-se de um perfil que merece maior atenção do Estado (por exemplo, nas ações do PLANAPO), uma vez que a demanda pelo consumo de produtos orgânicos vem crescendo no Brasil assim como em várias outras partes do mundo.

Palavras-chave: Agricultura orgânica, Censo Agropecuário 2006, perfil da produção.

\section{THE ORGANIC AGRICULTURE IN BRASIL: A PROFILE FROM CENSUS OF AGRICULTURE 2006}

\begin{abstract}
The main goal of this article is to analyze the profile of Brazilian organic production from the data of the Agricultural Census 2006, the last available. The paper identifies and quantifies the establishments producing organic by mapping the production and

\footnotetext{
1 Graduada em oceanologia (FURG). Mestre em Gerenciamento Costeiro (FURG). Doutoranda em Desenvolvimento Rural (UFRGS). E-mail: andreia.vigolo@gmail.com.

${ }_{2}$ Professor do Programa de Pós-Graduação em Desenvolvimento Rural (UFRGS). Doutor em Sociologia (UFRGS). E-mail: schneide@ufrgs.br.

3 Professor da Universidade Tecnológica Federal do Paraná (UTFPR). Doutor em Desenvolvimento Rural (UFRGS). E-mail: marciogazolla1@gmail.com.
} 
the producers profile, their socioeconomic characteristics and geographical regions where they are predominantly located. The methodology used was the analysis of secondary data from the Agricultural Census 2006 IBGE, taken from SIDRA website, using the key variable of establishments that made 'use of organic agriculture'. The results show that organic farming is not yet significant in Brazil. With regard to the socio economic profile, establishments that make use of organic agriculture are family farmers, especially those classified in Group B of PRONAF (which are the poorest), which participate in unions and/or professional associations. These farmers are mostly private owners of the land, with low level of education and with little or no access to technical assistance. The most common economic activities where organics are found are livestock and temporary crops. This is a profile that would deserve a high attention of the State (for example, in actions of the PLANAPO) because the demand of organic products to consumption is growing in Brazil and all over other parts of the world.

Keywords: Census of Agriculture 2006, organic agriculture, production profile.

\section{INTRODUÇÃO}

A produção e o consumo de alimentos orgânicos vêm crescendo de forma rápida no Brasil. O país segue a tendência global que sugere que a posição marginal que a produção e o consumo de alimentos orgânicos ocupavam está se modificando rapidamente. Estudos recentes (BLANC; KLEDAL, 2012; DALCIN et al., 2014; DIAS et al., 2015) indicam que a posição subordinada dos orgânicos não raro associada a um viés ideológico ou ligada ao ativismo político ambiental, está sendo ampliada e modificada pelo aumento da demanda. Os indicadores mais recentes mostram que atualmente existem cerca de 2 milhões de agricultores orgânicos no mundo cujo faturamento anual chega a 60 bilhões de dólares (FiBL; IFOAM, 2016). E o mais interessante: $80 \%$ destes produtores estão localizados em países em desenvolvimento, como o Brasil.

As razões que explicam o crescimento da demanda e da oferta de orgânicos são variadas: primeiro, as críticas ao modelo agroalimentar convencional, intensivo no uso de agroquímicos e com efeitos sobre a saúde e a biodiversidade, estão aumentando (PRETTY, 2002; IAASTD, 2009; BARANSKI et al., 2014; IPESFOOD, 2016); segundo, amplia-se a busca por alternativas de consumo de alimentos orgânicos (LAGO et al., 2006), frescos e naturais, fazendo com que a demanda se torne um drive importante de aumento dos mercados destes produtos (REGANOLD; WATCHER, 2016); terceiro, estudos e pesquisas científicas avançam no sentido de buscar novas técnicas e metodologias de produção orgânica (GODFRAY et al., 2010; PONISIO et al., 2016). Neste sentido, o cenário atual é muito distinto daquele de duas ou três décadas, em que a produção de orgânicos era vista como um hobby, uma atitude de protesto e o consumo como algo alternativo ou simplesmente um desvio dos padrões alimentares principais.

Obviamente que o crescimento da demanda e oferta de orgânicos não significa que estas representações ou práticas tenham desaparecido. Contudo, o fato novo é que os produtos orgânicos já não são marginais e nem somente encontrados nas pequenas feiras de produtos semanais ou consumidos por pessoas identificadas com um modo de vida culturalmente alternativo. Hoje em dia, é possível encontrar os orgânicos nas gôndolas dos grandes supermercados ou mesmo em lojas especializadas, quando não recomendados por grandes artistas, 
celebridades públicas ou decantados pelos chefs e gastrônomos como "a verdadeira comida" (WILLER; KILCHER, 2014; NIGEL, 2014).

Há pelo menos duas grandes perspectivas teóricas e políticas que avaliam este cenário e buscam explicar o crescimento e ampliação dos orgânicos. Por um lado, estão aqueles que consideram que se trata de uma 'janela de oportunidades' para o setor alimentar convencional ser hábil e rápido no sentido de perceber os orgânicos como um novo negócio, o que faz com que tanto a oferta quanto à demanda cresçam. Alguns autores mais críticos chamam esta vertente de 'convencionalização dos orgânicos' (GUTHMAN, 2004; NIEDERLE; ALMEIDA, 2013). Por outro lado, há os que acreditam que o crescimento da demanda por orgânicos tende a levar a uma segmentação e gerar disputas em torno do sentido dos 'verdadeiros alimentos', fazendo com que a agricultura de base ecológica passe a disputar teórica e politicamente o espaço dos orgânicos (GUZMÁN; WOODGATE, 2013; PETERSEN; MUSSOI; DAL SOGLIO, 2013). Independente das distintas denominações usadas (alternativa, orgânica, biodinâmica, ecológica e, mais recentemente, agroecológica) o fato é que a produção orgânica vem conquistando cada vez mais espaço, no campo produtivo, do consumo e nas análises científicas (GLIESSMAN, 2000; ALTIERI, 2004).

De acordo com dados mundiais compilados pelo Instituto de Pesquisa de Agricultura Orgânica (FiBL) e pela Federação Internacional dos Movimentos de Agricultura Orgânica (IFOAM), em 2016 foi estimada a quantia de 2,3 milhões de produtores, em 172 países, ocupando um total de 0,99\% de todas as terras cultivadas do planeta ${ }^{4}$. Em área, isso representou um salto de mais 0,5 milhões (em 2013) para 43,7 milhões de hectares cultivados em 2014. Somado às áreas orgânicas não agrícolas ${ }^{5}$ (35,1 milhões em 2013), obtêm-se um total de 78,2 milhões de hectares em todo o planeta. A Austrália lidera o ranking das maiores áreas de produção orgânica no mundo com 17,2 milhões de hectares, seguido pela Argentina (com 3,1 milhões) e pelos EUA (com 2,2 milhões). Na América Latina, a Argentina é o país que ocupa posição de destaque com 3,2 milhões de hectares orgânicos, seguido pelo Uruguai com 0,9 milhões e pelo Brasil com 0,7 milhões (FiBL; IFOAM, 2016).

No Brasil as informações sobre a agricultura orgânica ainda são escassas e dispersas, uma vez que são dados coletados pelas empresas de certificação ou por associações e ONGs que possuem atuação regional e local (MELÃO, 2010). O Ministério da Agricultura, Pecuária e Abastecimento (MAPA) criou o Cadastro Nacional de Produtores Orgânicos ${ }^{6}$, que registra um total de 13.438 organizações entre OPACs (Organismos Participativos de Avaliação da Conformidade) e OCS (Organização de Controle Social, que podem ser empresas ou cooperativas), que são pessoas jurídicas registrados com CNPJ (Cadastro Nacional de Pessoa Jurídica). Um estudo do SEBRAE (2010) descreveu o perfil do mercado de orgânicos no Brasil evidenciando que há uma tendência de aumento tanto na produção quanto no consumo. O trabalho de Dalcin et al. (2014) também mostrou que a venda de produtos orgânicos no Brasil aumentou 40\% entre 2009 e 2010 ,

${ }^{4}$ Os dados desta pesquisa incluem apenas a produção orgânica certificada ao longo do globo, portanto, representam números subestimados em sua totalidade.

${ }^{5}$ De acordo com IFOAM (2015), consideram-se como áreas não agrícolas aquelas voltadas à aquicultura, pastagens e áreas de floresta.

${ }^{6}$ Neste cadastro está a relação de Produtores Orgânicos de todo o Brasil, a listagem dos organismos que controlam a qualidade orgânica (OPAC - Organismos Participativos de Avaliação da Conformidade) e a listagem de organizações de controle social (OCS), que comercializam seus produtos diretamente ao consumidor. Ver em: http://www.agricultura.gov.br/desenvolvimento-sustentavel/organicos/cadastronacional. 
alcançando a faixa dos 190 milhões de dólares. Entretanto, ainda não há publicações nem trabalhos específicos que contemplem a análise dos dados do Censo Agropecuário abarcando o perfil da produção orgânica em todo o universo dos estabelecimentos agropecuários do Brasil. Assim, malgrado os dados tenham sido coletados para o ano agrícola de 2006 (embora a divulgação dos dados ocorreu apenas em 2009) uma visão mais acurada do cenário nacional somente é possível através do Censo Agropecuário, que ainda representa a base de dados agregada mais atual e completa sobre os estabelecimentos agropecuários de realizam produção orgânica no país.

Neste artigo pretendemos apresentar uma caracterização do perfil dos estabelecimentos agropecuários que fazem produção orgânica no Brasil, com base na sistematização e análise dos dados atualizados obtidos no Censo Agropecuário 2006. Pretende-se discutir os principais aspectos relacionados às características dos produtores, bem como a representatividade da agricultura orgânica no âmbito nacional, de forma a identificar 'um perfil médio' da agricultura orgânica brasileira.

Além desta introdução e das considerações finais, o artigo está estruturado em mais três seções. Na primeira, são apresentados os critérios e conceitos metodológicos da coleta de dados realizada pelo IBGE especificamente para o Censo 2006, bem como os procedimentos operacionais e metodológicos para a sistematização destes dados e informações. Na segunda são discutidos os resultados da sistematização dos dados secundários, buscando apresentar um panorama geral a respeito da agricultura orgânica no Brasil e nas Macrorregiões. Na terceira são evidenciadas as características dos estabelecimentos, levando em consideração diversos aspectos que caracterizam o perfil do agricultor orgânico.

\section{METODOLOGIA: OS ORGÂNICOS NO CENSO AGROPECUÁRIO 2006}

Existe consenso entre os estudiosos de que a agricultura brasileira tem sofrido mudanças estruturais desde a década de 1960, o que vem alterando suas características socioeconômicas, ambientais e produtivas (DELGADO, 2012; SCHNEIDER; FERREIRA; ALVES, 2014). Os Censos Agropecuários, realizados pelo IBGE, tem exercido um papel imprescindível para auxiliar a compreender estas mudanças, oferecendo periodicamente uma 'fotografia' sobre as características e o perfil do setor agropecuário nacional. O Censo de 2006, que é o último disponível, foi particularmente inovador, mediante a ampliação dos temas investigados e pela criação de uma segmentação entre estabelecimentos familiares e não-familiares. Mas vale destacar o acréscimo importante que se refere aos dados sobre a produção orgânica, que até então não era possível conhecer, permitindo assim dimensionar e caracterizar, de maneira ampla, a agricultura orgânica ${ }^{7}$ no cenário nacional (SOARES, 2015).

O Censo Agropecuário de 2006 (IBGE, 2017, p. 49) definiu, em sua metodologia, que a produção agrícola orgânica é realizada em:

estabelecimentos nos quais foram adotadas práticas de produção agropecuária que não utilizassem insumos artificiais (sendo eles: adubos químicos, agrotóxicos, organismos

\footnotetext{
${ }^{7}$ Neste artigo, os dados referentes à agricultura orgânica seguem a definição utilizada pelo IBGE, que não permitem estabelecer diferenciações entre os distintos modelos de agricultura orgânica, sejam quais forem os seus métodos de produção: ecológica, agroecológica, orgânica, biodinâmica ou outra denominação. Por isso, neste artigo, não serão detalhadas as diferentes modalidades e discussões teóricas que permeiam a chamada agricultura orgânica, uma vez que não há uma diferenciação na base de dados do Censo Agropecuário e nem na legislação vigente.
} 
geneticamente modificados ou outros), bem como outras medidas orientadas para a conservação dos recursos naturais e do meio ambiente.

Nesse sentido, foram quantificados também dados referentes à presença (ou em processo) de certificação orgânica da produção. Não foram considerados orgânicos aqueles estabelecimentos agropecuários que, mesmo não fazendo uso de insumos artificiais, desconheciam ou não tinham interesse nas técnicas exigidas pelas instituições certificadoras ${ }^{8}$. Mas foram levantados os estabelecimentos que utilizavam adubos orgânicos na produção, tais como: adubação verde, húmus de minhoca, biofertilizantes, vinhaça, inoculantes, esterco e urina animais ou outros compostos $^{9}$.

É importante ressaltar que a definição considerada para a coleta de dados do Censo difere do conceito de produção orgânica estabelecido na Lei no 10.831/2003 (BRASIL, 2003, p. 8), que considera como sistema orgânico de produção:

todo aquele em que se adotam técnicas específicas, mediante a otimização do uso dos recursos naturais e socioeconômicos disponíveis e o respeito à integridade cultural das comunidades rurais, tendo por objetivo a sustentabilidade econômica e ecológica, a maximização dos benefícios sociais, a minimização da dependência de energia não renovável, empregando, sempre que possível, métodos culturais, biológicos e mecânicos, em contraposição ao uso de materiais sintéticos, a eliminação do uso de organismos geneticamente modificados e radiações ionizantes, em qualquer fase do processo de produção, processamento, armazenamento, distribuição e comercialização, e a proteção do meio ambiente.

Sempre é válido frisar que o Censo Agropecuário utiliza como unidade básica de coleta das informações o estabelecimento agropecuário, que é definido como (IBGE, 2017, p. 40):

toda unidade de produção dedicada, total ou parcialmente, a atividades agropecuárias, florestais e aquícolas, subordinada a uma única administração: a do produtor ou a do administrador. Independente de seu tamanho, de sua forma jurídica ou de sua localização em área urbana ou rural, tendo como objetivo a produção para subsistência e/ou para venda, constituindo-se assim numa unidade recenseável.

\footnotetext{
${ }^{8}$ É importante salientar que, com base Decreto № 6.323/2007, a certificação orgânica pode ser obtida de duas maneiras: Sistemas Participativos de Garantia da Qualidade Orgânica e Certificação por Auditoria. Um trabalho interessante que aborda as diferenças entre as escolhas dos agricultores agroecológicos na adesão à certificação, que refletem dois setores político-econômicos distintos, pode ser encontrado em Comunello (2013).

${ }^{9}$ A partir da análise dos dados e de informações fornecidas pelo setor técnico do IBGE, constatou-se que existem 7 casos de agricultores que, em resposta ao Censo, consideraram-se produtores orgânicos, mas concomitantemente, faziam uso de agrotóxicos em pelo menos uma de suas lavouras. Em função disso, ocorreu uma superestimação de valores: aonde lê-se 90.498 estabelecimentos produtores de orgânicos, na prática, o valor exato seria 90.491 .
} 
Os estabelecimentos recenseados no Censo Agropecuário de 2006 também podem ser segmentados segundo critérios da agricultura familiar e não familiar, tomando-se por base a definição estabelecida pela Lei 11.326, de 24 de julho de 2006, também conhecida como a Lei da Agricultura Familiar (BRASIL, 2006; IBGE, 2009; DEL GROSSI; MARQUES, 2010), além de informações sobre o acesso ao Programa Nacional de Fortalecimento da Agricultura Familiar (PRONAF), entre outros.

Assim, é possível afirmar que o último Censo Agropecuário de 2006 ampliou a base de coleta de informações referentes às características do produtor (como sexo, idade, naturalidade, nível de instrução, tempo de direção do estabelecimento) assim como sobre as dimensões ambientais dos estabelecimentos agropecuários, expressos em informações coletadas sobre práticas agrícolas de conservação do solo, uso de queimadas, produtos utilizados na adubação e uso de agrotóxicos. A coleta de dados censitários também oferece informações sobre as características da produção, que incluem as formas de uso e aproveitamento da terra, agricultura orgânica, utilização de agrotóxicos e outros insumos, utilização de recursos técnicos e maquinário disponível, atividades aquícolas, manejo e conservação do solo.

Todos os dados secundários referentes ao Censo estão disponíveis em uma plataforma online, o Banco de Dados Agregados do Sistema de Recuperação Automática (SIDRA). Esta plataforma foi utilizada para acessar a base de dados do Censo Agropecuário, permitindo que a análise e sistematização das informações fossem divididas em três etapas. Primeiramente foi feita uma compilação de todas as tabelas de matrizes, inseridas no SIDRA, que contemplavam a categoria 'uso de agricultura orgânica'. A partir deste primeiro recorte, a segunda etapa consistiu em uma sistematização e tabulação dos usando-se o software Microsoft Excel. Isso possibilitou a construção de gráficos e tabelas ilustrativos, facilitando a visualização dos dados a serem analisados. Por fim, foi realizada uma análise crítica e a descrição dos dados sobre a agricultura orgânica no Brasil, que compõe o essencial da contribuição deste artigo.

\section{O PERFIL DA PRODUÇÃO ORGÂNICA NO BRASIL E MACRORREGIÕES}

Os dados do Censo evidenciam que, em 2006, dentre o total de 5.175.636 estabelecimentos agropecuários no Brasil, havia 90.498 que faziam uso de produção orgânica, representando $1,75 \%$ do total dos estabelecimentos (Tabela 1). Isso significa dizer que os, dentre todos os estabelecimentos agropecuários no país, menos de $2 \%$ utiliza algum tipo de técnica produtiva envolvendo as múltiplas dimensões do sistema orgânico, tanto pelo tipo de insumos utilizados, pela forma de manejo, produção de alimentos e adubação do solo ou alguma outra medida de conservação ambiental.

Dentre as regiões, quantitativamente a que mais se destaca é a Nordeste com 42.236 estabelecimentos agropecuários com produção orgânica, seguida pelo Sul com 19.276 estabelecimentos, e pelo Sudeste, com 18.715 estabelecimentos. Porém ao se considerar o número total de estabelecimentos agropecuários por região, a que mais se destaca em termos percentuais é a Sudeste, com 18.175 estabelecimentos com produção orgânica, representando 2,03\% do total. Seguida pela Região Sul, com 19.276 estabelecimentos agropecuários que fazem uso de agricultura orgânica (equivalente a $1,92 \%$ do total da região) e a Região Nordeste com 42.236 estabelecimentos (1,72\% do total da região). 
Tabela 1 - Distribuição dos estabelecimentos com agricultura orgânica no Brasil e Macrorregiões.

\begin{tabular}{cccccc}
\hline \multirow{2}{*}{$\begin{array}{c}\text { Brasil e } \\
\text { Regiões }\end{array}$} & \multirow{2}{*}{ Total } & \multicolumn{4}{c}{ Uso de agricultura orgânica } \\
\cline { 3 - 6 } & & \multicolumn{2}{c}{ Faz uso } & \multicolumn{2}{c}{ Não faz uso } \\
\cline { 2 - 5 } & & No estab. & \% & No estab. & $\%$ \\
\hline Brasil & 5.175 .636 & 90.498 & 1,75 & 5.085 .138 & 98,25 \\
Norte & 475.778 & 6.133 & 1,29 & 469.645 & 98,71 \\
Nordeste & 2.454 .060 & 42.236 & 1,72 & 2.411 .824 & 98,28 \\
Centro-Oeste & 317.498 & 4.138 & 1,30 & 313.360 & 98,70 \\
Sudeste & 922.097 & 18.715 & 2,03 & 903.382 & 97,97 \\
Sul & 1.006 .203 & 19.276 & 1,92 & 986.927 & 98,08 \\
\hline
\end{tabular}

Fonte: IBGE, Censo Agropecuário 2006.

De acordo com os dados do IBGE, a grande maioria dos estabelecimentos agropecuários orgânicos está inserida na categoria agricultura familiar (74.805 estabelecimentos, representando $82,66 \%$ do total), cuja representatividade é seguida também no âmbito macrorregional (Tabela 2). Contudo, nota-se que destes, 95,17\% não são certificados, evidenciando ser este um dos grandes desafios da agricultura orgânica no país (NIEDERLE; ALMEIDA, 2013). Regionalmente, os estabelecimentos familiares também se destacam neste tipo de agricultura. $O$ Nordeste tem o primeiro posto com $86,32 \%$, seguido pelo Sul $(83,51 \%)$ e pela Região Sudeste (75,28\%). Quanto à certificação orgânica entre as regiões brasileiras, os dados demonstram que ela é maior nas Regiões Sul $(9,62 \%$ na agricultura familiar - AF e 11,83\% na não familiar - ANF), seguido da Região Sudeste (5,90\% dos AF e $11,57 \%$ dos ANF) e em terceiro posto a Região Centro Oeste com $4,44 \%$ dos familiares e $9,78 \%$ dos estabelecimentos não familiares.

Tabela 2 - Distribuição dos estabelecimentos familiares e não familiares em relação à agricultura orgânica e certificação.

\begin{tabular}{|c|c|c|c|c|c|c|c|}
\hline \multirow{2}{*}{$\begin{array}{l}\text { Brasil e } \\
\text { Regiões }\end{array}$} & \multirow{2}{*}{$\begin{array}{l}\text { Agricultura } \\
\text { Familiar }\end{array}$} & \multicolumn{6}{|c|}{ Uso de agricultura orgânica } \\
\hline & & Total & $\%$ & Certificado & $\%$ & Não certificado & $\%$ \\
\hline \multirow[b]{2}{*}{ Brasil } & Sim & 74.805 & 82,66 & 3.616 & 4,83 & 71.189 & 95,17 \\
\hline & Não & 15.693 & 17,34 & 1.490 & 9,49 & 14.203 & 90,51 \\
\hline \multirow{2}{*}{ Norte } & Sim & 5.208 & 84,92 & 278 & 5,34 & 4.930 & 94,66 \\
\hline & Não & 925 & 15,08 & 73 & 7,89 & 852 & 92,11 \\
\hline \multirow{2}{*}{ Nordeste } & Sim & 36.458 & 86,32 & 828 & 2,27 & 35.630 & 97,73 \\
\hline & Não & 5.778 & 13,68 & 390 & 6,75 & 5.388 & 93,25 \\
\hline \multirow{2}{*}{ Sudeste } & Sim & 14.089 & 75,28 & 831 & 5,90 & 13.258 & 94,10 \\
\hline & Não & 4.626 & 24,72 & 535 & 11,57 & 4.091 & 88,43 \\
\hline \multirow{2}{*}{ Sul } & Sim & 16.098 & 83,51 & 1.548 & 9,62 & 14.550 & 90,38 \\
\hline & Não & 3.178 & 16,49 & 376 & 11,83 & 2.802 & 88,17 \\
\hline \multirow{2}{*}{$\begin{array}{l}\text { Centro- } \\
\text { Oeste }\end{array}$} & Sim & 2.952 & 71,34 & 131 & 4,44 & 2.821 & 95,56 \\
\hline & Não & 1.186 & 28,66 & 116 & 9,78 & 1.070 & 90,22 \\
\hline
\end{tabular}

Fonte: IBGE, Censo Agropecuário 2006.

Especificamente, no que se refere à certificação orgânica, ela também é tida como limitante à formalização das experiências. Um dos aspectos mencionados pelos estudos no Brasil, especialmente no formato auditado, são os altos custos envolvidos no processo de certificação dos alimentos orgânicos (BRANCHER, 2005). Em alguns, inclusive, há um desestímulo dos processos formais de reconhecimento das qualidades orgânicas dos alimentos, implicando em agricultores que preferem deixar a certificação (SCALCO; SERVI, 2014). Dentre os principais motivos alegados para isso estão: 0 alto custo da certificação, pouco reconhecimento da sociedade (os agricultores orgânicos recebem críticas de seus vizinhos de comunidade que não são orgânicos), exigências em torno do bem estar 
animal, infestação dos campos por doenças e pragas (diminuindo seus rendimentos) e suporte governamental insuficiente (KOESLING et al., 2012).

\section{CARACTERÍSTICAS DOS ESTABELECIMENTOS QUE PRATICAM AGRICULTURA ORGÂNICA}

$\mathrm{Na}$ maioria dos estabelecimentos agropecuários do Brasil os agricultores ostentam a condição de proprietários das terras (69.945 empreendimentos, representando $77,29 \%$ do total), seguido por ocupantes (7.796 estabelecimentos, representando 8,61\%) e assentados (5.091, representando 5,63\% do total), conforme evidenciado na Tabela 3 . Nota-se que os processos de certificação da produção a nível nacional estão mais presentes dentre os agricultores que são proprietários $(82,14 \%)$, seguidos pelos assentados $(5,95 \%)$ e pelos ocupantes $(5,21 \%)$. As demais categorias sociais possuem percentuais menores de $3 \% \mathrm{em}$ termos de certificação da produção.

Tabela 3 - Distribuição dos estabelecimentos com agricultura orgânica com base na condição do produtor e certificação.

(continua)

\begin{tabular}{|c|c|c|c|c|c|}
\hline \multirow{2}{*}{$\begin{array}{l}\text { Brasil e } \\
\text { Regiões }\end{array}$} & \multirow[b]{2}{*}{ Condição do produtor } & \multicolumn{4}{|c|}{ Uso de agricultura orgânica } \\
\hline & & Certificado & $\%$ & $\begin{array}{c}\text { Não } \\
\text { certificado }\end{array}$ & $\%$ \\
\hline \multirow{7}{*}{ Brasil } & Proprietário & 4.194 & 82,14 & 65.751 & 77,00 \\
\hline & Assentado sem titulação definitiva & 304 & 5,95 & 4.787 & 5,61 \\
\hline & Arrendatário & 166 & 3,25 & 2.212 & 2,59 \\
\hline & Parceiro & 100 & 1,96 & 1.991 & 2,33 \\
\hline & Ocupante & 266 & 5,21 & 7.530 & 8,82 \\
\hline & Produtor sem área & 76 & 1,49 & 3.121 & 3,65 \\
\hline & Total & 5.106 & 100,00 & 85.392 & 100,00 \\
\hline \multirow{7}{*}{ Norte } & Proprietário & 283 & 80,63 & 4.337 & 75,01 \\
\hline & Assentado sem titulação definitiva & 52 & 14,81 & 427 & 7,38 \\
\hline & Arrendatário & 1 & 0,28 & 52 & 0,90 \\
\hline & Parceiro & 2 & 0,57 & 107 & 1,85 \\
\hline & Ocupante & 11 & 3,13 & 668 & 11,55 \\
\hline & Produtor sem área & 2 & 0,57 & 191 & 3,30 \\
\hline & Total & 351 & 100,00 & 5.782 & 100,00 \\
\hline \multirow{7}{*}{ Nordeste } & Proprietário & 902 & 74,06 & 29.481 & 71,87 \\
\hline & Assentado sem titulação definitiva & 123 & 10,10 & 2.275 & 5,55 \\
\hline & Arrendatário & 21 & 1,72 & 1.223 & 2,98 \\
\hline & Parceiro & 21 & 1,72 & 1.410 & 3,44 \\
\hline & Ocupante & 106 & 8,70 & 4.593 & 11,20 \\
\hline & Produtor sem área & 45 & 3,69 & 2.036 & 4,96 \\
\hline & Total & 1.218 & 100,00 & 41.018 & 100,00 \\
\hline \multirow{7}{*}{ Sudeste } & Proprietário & 1.161 & 84,99 & 14.672 & 84,57 \\
\hline & Assentado sem titulação definitiva & 38 & 2,78 & 410 & 2,36 \\
\hline & Arrendatário & 56 & 4,10 & 379 & 2,18 \\
\hline & Parceiro & 47 & 3,44 & 303 & 1,75 \\
\hline & Ocupante & 51 & 3,73 & 1.129 & 6,51 \\
\hline & Produtor sem área & 13 & 0,95 & 456 & 2,63 \\
\hline & Total & 1.366 & 100,00 & 17.349 & 100,00 \\
\hline \multirow{7}{*}{ Sul } & Proprietário & 1.644 & 85,45 & 14.217 & 81,93 \\
\hline & Assentado sem titulação definitiva & 71 & 3,69 & 1.110 & 6,40 \\
\hline & Arrendatário & 78 & 4,05 & 489 & 2,82 \\
\hline & Parceiro & 30 & 1,56 & 158 & 0,91 \\
\hline & Ocupante & 87 & 4,52 & 960 & 5,53 \\
\hline & Produtor sem área & 14 & 0,73 & 418 & 2,41 \\
\hline & Total & 1.924 & 100,00 & 17.352 & 100,00 \\
\hline
\end{tabular}


(conclusão)

\begin{tabular}{|c|c|c|c|c|c|}
\hline \multirow{2}{*}{$\begin{array}{l}\text { Brasil e } \\
\text { Regiões }\end{array}$} & \multirow[b]{2}{*}{ Condição do produtor } & \multicolumn{4}{|c|}{ Uso de agricultura orgânica } \\
\hline & & Certificado & $\%$ & $\begin{array}{c}\text { Não } \\
\text { certificado }\end{array}$ & $\%$ \\
\hline \multirow{7}{*}{$\begin{array}{l}\text { Centro- } \\
\text { Oeste }\end{array}$} & Proprietário & 204 & 82,59 & 3.044 & 78,23 \\
\hline & Assentado sem titulação definitiva & 20 & 8,10 & 565 & 14,52 \\
\hline & Arrendatário & 10 & 4,05 & 69 & 1,77 \\
\hline & Parceiro & 0 & 0,00 & 13 & 0,33 \\
\hline & Ocupante & 11 & 4,45 & 180 & 4,63 \\
\hline & Produtor sem área & 2 & 0,81 & 20 & 0,51 \\
\hline & Total & $24 \overline{7}$ & 100,00 & 3.891 & 100,00 \\
\hline
\end{tabular}

Fonte: IBGE, Censo Agropecuário 2006.

Em todas as regiões também há prevalência de agricultores que são proprietários de suas terras no desenvolvimento da agricultura orgânica, tanto entre os certificados quanto entre os não certificados. Estes agricultores donos de terras que desenvolvem a agricultura orgânica estão mais presentes na Região Nordeste (mais de 30 mil estabelecimentos), seguida pelas Regiões Sul e Sudeste, ambas com em torno de 15 mil estabelecimentos. Em segundo lugar, em termos de condição do produtor em relação às terras, nas Regiões Norte e Centro Oeste prevalecem os agricultores assentados, seguidos pelos ocupantes. No Nordeste e no Sul inverte-se isso, os ocupantes estão à frente dos assentados. No Sudeste os ocupantes vêm depois dos agricultores proprietários. Isso demonstra que a posse da terra ou não como no caso dos ocupantes é muito variável por região e não é a regra para o desenvolvimento da agricultura orgânica, pois até os agricultores sem terra conseguem praticá-la (são 5,63\% a nível nacional).

Já com relação ao nível de instrução da pessoa que dirige o estabelecimento, a maioria dos chefes possui o ensino fundamental incompleto (37.639 estabelecimentos, representando 41,59\%), seguido por aqueles que não sabem ler e escrever (20.170 estabelecimentos, representando 22,29\%) e por aqueles que possuem ensino fundamental completo (7.872 estabelecimentos, representando 8,70\%) (Tabela 4). Dentre aqueles que fazem uso de agricultura orgânica certificada por entidade credenciada, destacam-se também os que possuem ensino fundamental incompleto (2.881, representando $44,67 \%$ do total de estabelecimentos certificados), valendo destacar a proporção significativamente maior de dirigentes de estabelecimentos com curso superior (492 estabelecimentos, representando $9,64 \%$ do total) comparativamente aos não certificados $(4,39 \%$ do total).

A Tabela 4 evidencia que, de maneira geral, os agricultores que praticam a agricultura orgânica possuem pouca instrução formal, o que nem sempre é impeditivo do desenvolvimento da mesma, pois suas bases assentam-se muito nos próprios conhecimentos locais, populares, tácitos e das próprias famílias, muitas vezes, sendo reproduzidos de uma geração para outra dentro da própria família como estudos tem evidenciado (GLIESSMAN, 2000; ALTIERI, 2004, OLIVEIRA; GAZOLLA; SCHNEIDER, 2011). Embora os conhecimentos formais possam ser importantes para estes agricultores ampliarem seus horizontes do saber e captar o 'campo de oportunidades' que estes novos mercados lhes oferecem. 
Tabela 4 - Distribuição dos estabelecimentos com agricultura orgânica em relação ao nível de instrução da pessoa que dirige o estabelecimento e certificação.

\begin{tabular}{|c|c|c|c|c|c|}
\hline \multirow[b]{2}{*}{$\begin{array}{l}\text { Brasil e } \\
\text { Regiões }\end{array}$} & \multirow[b]{2}{*}{$\begin{array}{l}\text { Nível de instrução da pessoa que } \\
\text { dirige o estabelecimento }\end{array}$} & \multicolumn{4}{|c|}{ Uso de agricultura orgânica } \\
\hline & & $\begin{array}{l}\text { Certifica- } \\
\text { do }\end{array}$ & $\%$ & $\begin{array}{c}\text { Não } \\
\text { certificado }\end{array}$ & $\%$ \\
\hline \multirow{9}{*}{ Brasil } & Alfabetização de adultos & 220 & 4,31 & 4.242 & 4,97 \\
\hline & Ens. fund. inc. ( $1^{\circ}$ grau $)$ & 2.281 & 44,67 & 35.358 & 41,41 \\
\hline & Ens.fund. comp. (1ํgrau) & 639 & 12,51 & 7.233 & 8,47 \\
\hline & Ens. médio ou $2^{\circ}$ grau comp. & 232 & 4,54 & 1.631 & 1,91 \\
\hline & Ens. médio ou $2^{\circ}$ grau comp. & 628 & 12,30 & 6.239 & 7,31 \\
\hline & Formação superior & 492 & 9,64 & 3.747 & 4,39 \\
\hline & Nenhum, mas sabe ler e escr. & 292 & 5,72 & 7.094 & 8,31 \\
\hline & Não sabe ler e escrever & 322 & 6,31 & 19.848 & 23,24 \\
\hline & Total & 5.106 & 100,00 & 85.392 & 100,00 \\
\hline \multirow{9}{*}{ Norte } & Alfabetização de adultos & 57 & 16,24 & 357 & 6,17 \\
\hline & Ens. fund. inc. ( $\left.1^{\circ} \mathrm{grau}\right)$ & 148 & 42,17 & 2.863 & 49,52 \\
\hline & Ens. fund. comp. (1ํgrau) & 38 & 10,83 & 409 & 7,07 \\
\hline & Ens. médio ou $2^{\circ}$ grau comp. & 14 & 3,99 & 107 & 1,85 \\
\hline & Ens. médio ou $2^{\circ}$ grau comp. & 24 & 6,84 & 377 & 6,52 \\
\hline & Formação superior & 12 & 3,42 & 134 & 2,32 \\
\hline & Nenhum, mas sabe ler e esc. & 28 & 7,98 & 488 & 8,44 \\
\hline & Não sabe ler e escrever & 30 & 8,55 & 1.047 & 18,11 \\
\hline & Total & 351 & 100,00 & 5.782 & 100,00 \\
\hline \multirow{9}{*}{ Nordeste } & Alfabetização de adultos & 62 & 5,09 & 2.237 & 5,45 \\
\hline & Ens. fund. inc. (1ํgrau) & 442 & 36,29 & 13.254 & 32,31 \\
\hline & Ens. fund. comp. (1ํgrau) & 108 & 8,87 & 2.215 & 5,40 \\
\hline & Ens. médio ou $2^{\circ}$ grau comp. & 58 & 4,76 & 558 & 1,36 \\
\hline & Ens. médio ou $2^{\circ}$ grau comp. & 121 & 9,93 & 2.191 & 5,34 \\
\hline & Formação superior & 112 & 9,20 & 1.057 & 2,58 \\
\hline & Nenhum, mas sabe ler e escr. & 125 & 10,26 & 4.243 & 10,34 \\
\hline & Não sabe ler e escrever & 190 & 15,60 & 15.263 & 37,21 \\
\hline & Total & 1.218 & 100,00 & 41.018 & 100,00 \\
\hline \multirow{9}{*}{ Sudeste } & Alfabetização de adultos & 53 & 3,88 & 792 & 4,57 \\
\hline & Ens. fund. inc. ( $1^{\circ}$ grau $)$ & 577 & 42,24 & 7.376 & 42,52 \\
\hline & Ens. fund. comp. (1ำ grau) & 165 & 12,08 & 1.930 & 11,12 \\
\hline & Ens. médio ou $2^{\circ}$ grau comp. & 62 & 4,54 & 455 & 2,62 \\
\hline & Ens. médio ou $2^{0}$ grau comp. & 199 & 14,57 & 1.676 & 9,66 \\
\hline & Formação superior & 208 & 15,23 & 1.327 & 7,65 \\
\hline & Nenhum, mas sabe ler e esc. & 50 & 3,66 & 1.427 & 8,23 \\
\hline & Não sabe ler e escrever & 52 & 3,81 & 2.366 & 13,64 \\
\hline & Total & 1.366 & 100,00 & 17.349 & 100,00 \\
\hline \multirow{9}{*}{ Sul } & Alfabetização de adultos & 40 & 2,08 & 585 & 3,37 \\
\hline & Ens. fund. inc. ( $1^{\circ}$ grau $)$ & 1.011 & 52,55 & 10.081 & 58,10 \\
\hline & Ens. fund. comp. (1ำ grau) & 294 & 15,28 & 2.208 & 12,72 \\
\hline & Ens. médio ou $2^{\circ}$ grau comp. & 80 & 4,16 & 368 & 2,12 \\
\hline & Ens. médio ou $2^{0}$ grau comp. & 245 & 12,73 & 1.533 & 8,83 \\
\hline & Formação superior & 128 & 6,65 & 888 & 5,12 \\
\hline & Nenhum, mas sabe ler e esc. & 84 & 4,37 & 753 & 4,34 \\
\hline & Não sabe ler e escrever & 42 & 2,18 & 936 & 5,39 \\
\hline & Total & 1.924 & 100,00 & 17.352 & 100,00 \\
\hline \multirow{9}{*}{$\begin{array}{l}\text { Centro- } \\
\text { Oeste }\end{array}$} & Alfabetização de adultos & 8 & 3,24 & 271 & 6,96 \\
\hline & Ens. fund. inc. (1ㅇa grau) & 103 & 41,70 & 1.784 & 45,85 \\
\hline & Ens. fund. comp. (1ํgrau) & 34 & 13,77 & 471 & 12,10 \\
\hline & Ens. médio ou $2^{\circ}$ grau comp. & 18 & 7,29 & 143 & 3,68 \\
\hline & Ens. médio ou $2^{0}$ grau comp. & 39 & 15,79 & 462 & 11,87 \\
\hline & Formação superior & 32 & 12,96 & 341 & 8,76 \\
\hline & Nenhum, mas sabe ler e esc. & 5 & 2,02 & 183 & 4,70 \\
\hline & Não sabe ler e escrever & 8 & 3,24 & 236 & 6,07 \\
\hline & Total & 247 & 100,00 & 3.891 & 100,00 \\
\hline
\end{tabular}

Fonte: IBGE, Censo Agropecuário 2006. 
A Tabela 5 traz a área ocupada pelos estabelecimentos orgânicos no Brasil e macrorregiões. A agricultura orgânica ocupa 4.935.358 hectares, representando $2,24 \%$ do total das terras utilizadas pela agropecuária no Brasil. Dentre as macrorregiões, a que mais se destaca é o Sul, cuja produção orgânica ocupa 3,31\% da área cultivada (539.521 ha), inclusive, com área acima da média do país. Com quase $3 \%$ das áreas com cultivos orgânicos estão as Regiões Sudeste (2,98\%) e o Nordeste (2,90\%). Já a Região Norte possui o menor percentual, apenas 1,39\%.

Tabela 5 - Área ocupada pelos estabelecimentos com agricultura orgânica no Brasil e Macrorregiões.

\begin{tabular}{lcrrrr}
\hline \multirow{2}{*}{ Brasil e Regiões } & \multirow{2}{*}{$\begin{array}{c}\text { Total } \\
\text { (hectares) }\end{array}$} & \multicolumn{4}{c}{ Uso de agricultura orgânica } \\
\cline { 3 - 6 } & & \multicolumn{2}{c}{ Faz uso } & \multicolumn{2}{c}{ Não faz uso } \\
\cline { 3 - 6 } & 220.773 .071 & 4.935 .358 & 2,24 & 215.837 .713 & 97,76 \\
\hline Brasil & 44.370 .311 & 618.030 & 1,39 & 43.752 .280 & 98,61 \\
Norte & 54.367 .641 & 1.574 .001 & 2,90 & 52.793 .640 & 97,10 \\
Nordeste & 32.520 .033 & 970.686 & 2,98 & 31.549 .347 & 97,02 \\
Sudeste & 16.300 .661 & 539.521 & 3,31 & 15.761 .140 & 96,69 \\
Sul & 73.214 .426 & 1.233 .119 & 1,68 & 71.981 .306 & 98,32 \\
Centro-Oeste & & & & & \\
\hline
\end{tabular}

Fonte: IBGE, Censo Agropecuário 2006.

Com base na análise por grupos de área total é possível evidenciar que a maioria dos estabelecimentos orgânicos possui de 20 a menos de 50 ha, num total de 13.884 estabelecimentos, representando $15,34 \%$ de todos os estabelecimentos orgânicos do país (Tabela 6). Na sequência, destacam-se os estabelecimentos de 10 a menos de 20 ha (12.525, representando 13,84\%) e de 5 a menos de 10 ha (11.894, representando $13,14 \%$ ). Entre os estabelecimentos de uso de agricultura orgânica certificados por entidade credenciada, os mais proeminentes são os do grupo de 10 a menos de 20 ha (são 978 estabelecimentos).

Vale ressaltar que a média e a grande agricultura também possuem um papel importante no desenvolvimento da agricultura orgânica. Embora os estabelecimentos contidos nos grupos de área acima de 50 ha sejam menos numerosos dos que os abaixo desta linha de corte, estes estabelecimentos possuem maiores áreas de terras usadas na prática da agricultura orgânica, o que pode levar, hipoteticamente, a produção de maiores volumes (um caso emblemático é o do café orgânico, por exemplo). Assim, os dados da Tabela 6 permitem verificar que nas pequenas propriedades rurais (menores de 50 ha) se concentra a maioria dos estabelecimentos agropecuários que realizam produção orgânica no país, embora esse dado não permita verificar em que tipo agricultura (familiar, médios agricultores ou não familiar) se concentra a maior parte da produção orgânica. 
Tabela 6 - Distribuição dos estabelecimentos com agricultura orgânica segundo grupos de área e por processo de certificação.

\begin{tabular}{lrrrrr}
\hline \multirow{2}{*}{ Grupos de área total } & \multicolumn{5}{c}{ Uso de agricultura orgânica } \\
\cline { 2 - 5 } & Total & Certificado & $\%$ & Não certificado & $\%$ \\
\hline Mais de 0 a menos de 0,1 ha & 2.081 & 42 & 2,02 & 2.039 & 97,98 \\
De 0,1 a menos de 0,2 ha & 1.119 & 34 & 3,04 & 1.085 & 96,96 \\
De 0,2 a menos de 0,5 ha & 2.920 & 78 & 2,67 & 2.842 & 97,33 \\
De 0,5 a menos de 1 ha & 5.081 & 132 & 2,60 & 4.949 & 97,40 \\
De 1 a menos de 2 ha & 8.336 & 314 & 3,77 & 8.022 & 96,23 \\
De 2 a menos de 3 ha & 6.706 & 278 & 4,15 & 6.428 & 95,85 \\
De 3 a menos de 4 ha & 5.163 & 223 & 4,32 & 4.940 & 95,68 \\
De 4 a menos de 5 ha & 4.065 & 221 & 5,44 & 3.844 & 94,56 \\
De 5 a menos de 10 ha & 11.894 & 813 & 6,84 & 11.081 & 93,16 \\
De 10 a menos de 20 ha & 12.525 & 978 & 7,81 & 11.547 & 92,19 \\
De 20 a menos de 50 ha & 13.884 & 916 & 6,60 & 12.968 & 93,40 \\
De 50 a menos de 100 ha & 6.474 & 417 & 6,44 & 6.057 & 93,56 \\
De 100 a menos de 200 ha & 3.359 & 246 & 7,32 & 3.113 & 92,68 \\
De 200 a menos de 500 ha & 2.343 & 191 & 8,15 & 2.152 & 91,85 \\
De 500 a menos de 1000 ha & 726 & 78 & 10,74 & 648 & 89,26 \\
De 1000 a menos de 2500 ha & 418 & 37 & 8,85 & 381 & 91,15 \\
De 2500 ha e mais & 207 & 32 & 15,46 & 175 & 84,54 \\
Produtor sem área & 3.197 & 76 & 2,38 & 3.121 & 97,62 \\
\hline
\end{tabular}

Fonte: IBGE, Censo Agropecuário 2006.

No que se refere ao acesso à orientação técnica, os dados do Censo Agropecuário mostram um quadro precário tanto nos estabelecimentos com produção orgânica certificados como entre os não certificados: $75,19 \%$ (60.845) de todos os estabelecimentos com uso de agricultura orgânica no Brasil não receberam nenhum tipo de orientação em 2006. Já os que recebem regularmente são apenas 9.308 estabelecimentos, representando 10,29\% do total. Entre o grupo dos certificados não há valores discrepantes entre os que recebem orientação técnica regularmente (1.683 estabelecimentos, representando $32,96 \%$ ) e os que nunca receberam (1.983 estabelecimentos, representando 38,94\%). Já entre o grupo dos não certificados, os valores são bastante distantes: enquanto 66.062 estabelecimentos nunca receberam orientação técnica (representando $77,36 \%$ do total), apenas 7.625 estabelecimentos recebem orientação com regularidade (representando 8,93\%). Estes dados indicam a hipótese de que a menor certificação por parte de alguns estabelecimentos pode estar relacionada à falta de acompanhamento técnico dos agricultores e das práticas orgânicas de produção.

Regionalmente, os dados indicam que o Nordeste e o Norte são as duas regiões em que os agricultores menos recebem orientação técnica em relação à produção contida nos estabelecimentos. Na sequência vêm as Regiões Sudeste e Centro Oeste. A Região Sul aparece como a que mais orientação técnica os estabelecimentos tem recebido, comparativamente às demais do país ${ }^{10}$.

Com relação à associação a cooperativas e/ou entidades de classe, no contexto nacional verifica-se que a grande maioria dos agricultores orgânicos certificados são associados a estas entidades (37,83\% dos certificados e $31,09 \%$ dos não certificados), sendo as entidades de classe predominantes (19,53\% dos certificados e $25,43 \%$ dos não certificados), seguido pelas cooperativas $(9,79 \%$ dos certificados e $3,68 \%$ dos não certificados). Isso sugere que estes agricultores preferem desenvolver a agricultura orgânica juntamente com essas organizações sociais coletivas e de representação política, especialmente sindicatos e cooperativas.

${ }^{10}$ Por restrições de espaço do trabalho várias tabelas e gráficos não puderam estar presentes no texto; optou-se, assim, por apresentá-los apenas textualmente, referindo-se somente aos dados e discutindo-os. 
Entretanto, há um percentual não desprezível de em torno de mais de $1 / 4$ dos estabelecimentos que optam por não pertencer a nenhum tipo de associação, sendo este percentual maior dentre os não certificados $(37,82 \%)$ do que nos certificados $(24,34 \%)$, sugerindo que os primeiros possuem menos ações coletivas no desenvolvimento de sua produção orgânica. Neste sentido, é possível perceber uma correlação direta entre processo de certificação e associação: enquanto grande parte dos agricultores orgânicos certificados estão associados a alguma cooperativa ou entidade de classe, entre os que não estão certificados a maioria não possui vínculo associativo e quando o possui, os percentuais são menores.

Em relação à classificação dos agricultores orgânicos dentro das categorias da agricultura familiar (AF) e não familiar (ANF), a Tabela 7 evidencia esta tipologia, segregando os AF pelos grupos do PRONAF, segundo os critérios do Plano Safra 2006/07 (indica o público potencial que poderia acessar o programa). A Tabela 7 evidencia que do total de estabelecimentos que realizam agricultura orgânica, 22.090 não pertencem ao publico potencial para acesso ao PRONAF, mas uma parcela muito significativa de 68.408 estabelecimentos, o que representa $75,59 \%$ do total, são enquadrados como potencial de acesso a alguma das modalidades do PRONAF. Isso autoriza a afirmar que o PRONAF tem sido uma política pública com interfaces consistentes com a produção orgânica.

Entre os estabelecimentos com agricultura orgânica que são potenciais beneficiários do PRONAF, destacam-se aqueles enquadrados no Grupo B (39.996 estabelecimentos, representando $44,20 \%$ do total) e os agricultores enquadrados no Grupo A do PRONAF (assentados da reforma agrária) com $11,85 \%$ do total dos estabelecimentos orgânicos a nível nacional (10.724 estabelecimentos). Se somados, estes dois grupos sociais de agricultores perfazem mais de $55 \%$ dos estabelecimentos que produzem orgânicos. Estes dois grupos são justamente os agricultores de menor renda econômica, embora a ampla maioria não esteja certificada, o que certamente traz algum limitante para que possam acessar e construir estes mercados sustentáveis.

Tabela 7 - Classificação dos estabelecimentos com agricultura orgânica que possuem acesso ao PRONAF, segundo os Grupos do programa.

\begin{tabular}{lrrrrrr}
\hline \multirow{2}{*}{ Grupos } & \multicolumn{7}{c}{ Uso de agricultura orgânica } \\
\cline { 2 - 7 } & \multicolumn{1}{c}{ Total } & \multicolumn{1}{c}{$\%$} & Certificado & \multicolumn{1}{c}{ \% } & Não certificado & \% \\
\hline Não Pronaf & 22.090 & 24,41 & 1.842 & 36,08 & 20.248 & 23,71 \\
Pronaf A & 10.724 & 11,85 & 606 & 11,87 & 10.118 & 11,85 \\
Pronaf B & 39.996 & 44,20 & 1.096 & 21,46 & 38.900 & 45,55 \\
Pronaf C & 13.802 & 15,25 & 1.125 & 22,03 & 12.677 & 14,85 \\
Pronaf D & 3.221 & 3,56 & 388 & 7,60 & 2.833 & 3,32 \\
Pronaf E & 665 & 0,73 & 49 & 0,96 & 616 & 0,72 \\
Total & $\mathbf{9 0 . 4 9 8}$ & $\mathbf{1 0 0 , 0 0}$ & $\mathbf{5 . 1 0 6}$ & $\mathbf{1 0 0 , 0 0}$ & $\mathbf{8 5 . 3 9 2}$ & $\mathbf{1 0 0 , 0 0}$ \\
\hline
\end{tabular}

Fonte: IBGE, Censo Agropecuário 2006.

Os trabalhos de Aquino (2014) demonstram que os agricultores do Grupo B do PRONAF estão localizados principalmente nos estados do Nordeste (65\% dos estabelecimentos) e em Minas Gerais, caracterizando-se por possuírem baixa renda bruta (até $R \$ 3.000,00 / a n o)$. Outros estudos pontais realizados no Sul e no Nordeste do Brasil (AQUINO, 2014; AQUINO; GAZOLLA; SCHNEIDER, 2015) indicam que estes agricultores possuem "múltiplas vulnerabilidades", que vão desde limitações nos ativos produtivos (pouca terra e produção, com exceção do autoconsumo), nos resultados econômicos (renda e VBP baixos), carências sociais (baixos índices de escolaridade, idade avançada das pessoas que dirigem 0 estabelecimento, cooperam muito pouco, quase não recebem assistência técnica), até restrições técnicas (usam poucas tecnologias) e problemas climáticos (as secas no caso do 
Nordeste). Embora seja um grupo social com múltiplas carências sociais e produtivas, estes agricultores demonstram uma impressionante resiliência e capacidade de adaptação, o que é muito importante aos processos de desenvolvimento sustentável da agricultura brasileira.

Vale registrar que a Tabela 7 oferece uma informação adicional sobre os 22.090 estabelecimentos de agricultores que não são potenciais de acessarem o PRONAF. Na verdade, não é possível afirmar que se trata de agricultores familiares que fazem produção orgânica, pois de acordo com o IBGE esta categoria inclui os estabelecimentos com agricultura não familiar e familiar não PRONAF. Entretanto, este grupo social aparece como importante em número de estabelecimentos que fazem produção orgânica no Brasil, ficando com $24,41 \%$ dos estabelecimentos produtores.

Os agricultores que acessam o PRONAF e pertencem ao Grupo C, podem ser considerados os agricultores 'intermediários' (PICOLOTTO, 2012), aparecem com $15,25 \%$ da produção orgânica. Outro dado importante desta tabela 7 refere-se aos produtores classificados como pertencentes aos grupos $D$ e $E$, que são estabelecimentos de agricultores familiares 'melhor estruturados', mostrando que estes atingem uma parcela de apenas $5 \%$, dos estabelecimentos que fazem agricultura orgânica. Entretanto, quando se soma os familiares 'mais estruturados (Grupos D e E) com os agricultores Não PRONAF, que formam o segmento mais dinâmico da 'agricultura moderna' brasileira, nota-se que estes respondem por um percentual considerável de em torno de $1 / 3$ dos estabelecimentos que praticam agricultura orgânica no país (28,7\% dos estabelecimentos).

Os dados mostram ainda que embora os agricultores 'mais estruturados e modernos' sejam representativos no número de estabelecimentos orgânicos, são os agricultores familiares mais pobres que representam a parcela numericamente mais significativa de estabelecimentos que fazem produção orgânica no país. Estes dados podem ser tomados como indicadores importantes para análises mais aprofundadas que devem levar em conta o contexto social no qual tais estabelecimentos estão inseridos. Não deixa de ser interessante observar que talvez aí resida uma potencial vantagem competitiva para alguns produtores, malgrado o fato de que sua produção não contar com certificação e, talvez por isso, sofra restrições para acessar e construir novos mercados.

Em relação à certificação, os dados da Tabela 7 mostram que os agricultores familiares que não acessam o PRONAF são os que possuem maior porcentagem (36,08\% dos mesmos), seguidos pelos do Grupo C (22,03\%) e B $(21,46 \%)$, que possuem percentuais muito próximos. Dentre os não certificados, os maiores percentuais encontram-se no Grupo B (45,55\%), seguidos dos não PRONAF (23,71\%) e do Grupo C (14,85\%). Os dados evidenciam a dificuldade de acesso dos agricultores mais pobres aos processos de certificação da produção, devido às suas múltiplas carências, como assinalado acima.

Para estes agricultores mais fragilizados do campo e que respondem pelos maiores percentuais de estabelecimentos com agricultura orgânica brasileira, seria muito importante o Estado prover os mesmos de maior apoio e fortalecê-los com políticas públicas voltadas ao desenvolvimento sustentável, tanto do ponto de vista da produção, mas também de comercialização, certificação, logística, assistência técnica, entre outras. Assim, um aprofundamento mais efetivo das ações multidimensionais propostas pelo PLANAPO (Plano Nacional de Agroecologia e 
Produção Orgânica) seria fundamental para beneficiar estes estabelecimentos e agricultores ecológicos (SAMBUICHI et al., 2016) ${ }^{11}$.

A atividade econômica prevalecente na produção orgânica é a pecuária e criação de outros animais (38.680, representando $42,74 \%$ do total), sendo essa magnitude mantida tanto dentre os estabelecimentos certificados quanto entre os não certificados (nos quais a pecuária responde com 36,88\% e 43,09\%, respectivamente) (Tabela 8 ). Os estabelecimentos com lavoura temporária possuem expressividade um pouco menor: são 29.656 estabelecimentos, representando $32,77 \%$ do total. As atividades de lavoura permanente ocorrem em 9.541 estabelecimentos e representam $10,54 \%$ do total. As atividades onde a agricultura orgânica é menos importante são a produção de sementes e mudas, pesca e aquicultura, tanto no caso dos certificados como dos não certificados, todos possuem percentuais menores que $0,5 \%$.

Tabela 8 - Estabelecimentos agropecuários com agricultura orgânica por grupos de atividades econômica.

\begin{tabular}{lrrrrrr}
\hline \multirow{2}{*}{ Grupos de atividade econômica } & \multicolumn{6}{c}{ Uso da agricultura orgânica } \\
\cline { 2 - 7 } & \multicolumn{1}{c}{ Total } & \multicolumn{1}{c}{$\%$} & Certif. & \multicolumn{1}{c}{$\%$} & Não Certif. & $\%$ \\
\hline Lavoura temporária & 29.656 & 32,77 & 1.025 & 20,07 & 28.631 & 33,53 \\
\hline Horticultura e floricultura & 8.840 & 9,77 & 1.012 & 19,82 & 7.828 & 9,17 \\
Lavoura permanente & 9.541 & 10,54 & 1.033 & 20,23 & 8.508 & 9,96 \\
Sementes, mudas e outras & 51 & 0,06 & 8 & 0,16 & 43 & 0,05 \\
Pecuária e criação de outros animais & 38.680 & 42,74 & 1.883 & 36,88 & 36.797 & 43,09 \\
Florestas plantadas & 1.581 & 1,75 & 64 & 1,25 & 1.517 & 1,78 \\
Florestas nativas & 1.633 & 1,80 & 56 & 1,10 & 1.577 & 1,85 \\
Pesca & 153 & 0,17 & 1 & 0,02 & 152 & 0,18 \\
Aquicultura & 363 & 0,40 & 24 & 0,47 & 339 & 0,40 \\
Total & $\mathbf{9 0 . 4 9 8}$ & $\mathbf{1 0 0 \%}$ & $\mathbf{5 . 1 0 6}$ & $\mathbf{1 0 0 \%}$ & $\mathbf{8 5 . 3 9 2}$ & $\mathbf{1 0 0 \%}$ \\
\hline
\end{tabular}

Fonte: IBGE, Censo Agropecuário 2006.

Com relação à produção agropecuária e as áreas colhidas, foi possível verificar que a atividade agrícola que mais se destaca é a produção das lavouras temporárias com $R \$ 420.332,00$ (mil reais) de valor da produção e 44.527 .696 ha de área colhida. Em segundo posto aparece à pecuária e a criação de outros animais com um valor da produção de $R \$ 45.279,00$ (em mil reais) e uma área de criação de 4.617.776 ha. As demais atividades como as lavouras permanentes, horticultura e fruticultura e a produção de florestas nativas ocupam números intermediários de valores da produção e das áreas colhidas. As atividades com menores valores de produção e área colhidas são, respectivamente: florestas plantadas, seguidas da produção de sementes, mudas e aquicultura e pesca.

\section{CONSIDERAÇÕES FINAIS}

De maneira geral, o perfil 'médio' do agricultor orgânico brasileiro pode ser descrito como um estabelecimento de agricultura familiar, que no geral não está certificado por entidade credenciada e possui área produtiva de tamanho pequeno a

\footnotetext{
${ }^{11}$ Não dizer que somente a ação do Estado seja fundamental para viabilizar a produção orgânica brasileira em níveis maiores dos que existentes atualmente. Esta deve ser balanceada com as iniciativas postas em práticas pelos próprios atores sociais e suas organizações como as cooperativas, entidades de classe e sindicatos aos quais os agricultores participam ativamente, conforme os dados apresentados no texto evidenciam. Quando se refere ao Estado ser mais ativo no apoio a produção orgânica e a agroecologia, está-se referindo-se as ações no âmbito do PLANAPO, que segundo algumas análises e estudos, não conseguiu alcançar grande parte dos objetivos e metas propostas. Ver, por exemplo, as análises de Ciapo (2016), Oliveira (2016) e Sambuichi el al. (2016).
} 
médio (variando entre 10 e 50 ha). Os estabelecimentos agropecuários que fazem uso de agricultura orgânica representam apenas 1,75\% (dos 90.498) do total dos estabelecimentos agropecuários do Brasil, dos quais $82,66 \%$ são familiares e $94,4 \%$ não estão certificados. Embora $1 / 3$ dos estabelecimentos que praticam a agricultura orgânica sejam de agricultores familiares e não familiares 'mais estruturados' e dinâmicos da agropecuária nacional. A Região Nordeste é a que possui o maior número de estabelecimentos agropecuários que fazem uso de agricultura orgânica (42.236, o que corresponde a $1,72 \%$ do total de estabelecimentos agropecuários do Brasil). Porém, em termos de proporção de estabelecimentos orgânicos, a região Sudeste é a que se destaca, com $2,03 \%$ do total.

Os agricultores com produção orgânica são, em sua maioria, proprietários das terras que cultivam, possuem baixo grau de escolarização e contam com pouca ou nenhuma orientação da assistência técnica. Em geral, são estabelecimentos associados a entidades de classe (sindicatos) e/ou a cooperativas e são potenciais beneficiários aos financiamentos do PRONAF. Do ponto de vista econômico é importante frisar que são os agricultores mais pobres que respondem por mais da metade da produção orgânica nacional (público potencial do Grupo B e A do PRONAF), apesar de ainda serem necessários estudos complementares para se saber qual o impacto socioambiental desse processo. As atividades agropecuárias que mais se destacam entre os estabelecimentos que fazem produção orgânica são a pecuária e as lavouras temporárias. Os números do Censo Agropecuário 2006 também revelam uma enorme disparidade entre os estabelecimentos certificados e não certificados, evidenciando dificuldades de acesso à certificação pelos agricultores.

As análises a partir dos dados do Censo evidenciam que a agricultura orgânica no Brasil ainda é pouco expressiva, tanto com relação ao número de estabelecimentos agropecuários quando no que diz respeito à área total cultivada. Porém, no contexto mundial, o Brasil possui lugar significativo em termos de área de produção orgânica, principalmente frente à América Latina.

A contribuição da agricultura familiar para a produção orgânica no Brasil é de grande relevância e significado. Estes dados estatísticos corroboram com análises de outros estudiosos como Altieri e Toledo (2011), que afirmam que o predomínio da agricultura familiar decorre de uma série de fatores histórico-culturais, mas principalmente o fato de que estes segmentos de mercados ainda despertam pouco interesse por parte da agricultura não familiar. Esta avaliação também é compartilhada no Brasil por Niederle e Almeida (2013), que chamam a atenção para três elementos: a baixa demanda por orgânicos; a carência de tecnologias adaptadas; e, mais fortemente, a ausência de um contexto político-institucional que 'garanta estabilidade à dinâmica dos mercados' de orgânicos no país. Não obstante, há indícios de que este quadro esteja se alterando, tendo em vista o desenvolvimento de tecnologias apropriadas, o aumento da demanda nos mercados, a mudança de opinião dos consumidores e as nascentes políticas públicas voltadas à agroecologia e produção orgânica.

Em face do reconhecido potencial da agricultura orgânica e de seu papel para o desenvolvimento sustentável e, sobretudo, tendo em vista o rápido crescimento da demanda por produtos orgânicos no Brasil, acredita-se que o perfil apresentado neste estudo sugere a necessidade de uma atenção maior do Estado brasileiro em relação a este setor, especialmente, por que o mesmo é composto de agricultores familiares pequenos e com múltiplas carências socioeconômicas e produtivas.

Como os estabelecimentos agropecuários que praticam a produção orgânica em geral estão organizados em torno de cooperativas e associações, as 
ações do Estado e as políticas públicas poderiam se beneficiar desta capacidade organizacional para tornar mais efetivas as ações e políticas. Vale citar como exemplo, as diretrizes e ações contidas no PLANAPO, que poderiam ser mais efetivas e operacionais em apoiar a agricultura orgânica, via aumento do número de estabelecimentos produtores, bem como maior acesso ao crédito rural, políticas de comercialização, ênfase na certificação e ATER voltadas as atividades ecológicas.

\section{REFERÊNCIAS}

ALTIERI M. A.; TOLEDO V. M. The agroecological revolution in Latin America. Journal of Peasant Studies. v. 38, p. 587-612, 2011.

ALTIERI, M. A. Agroecologia: a dinâmica produtiva da agricultura sustentável. Porto Alegre: Editora da UFRGS, 4aㅡ ed., 2004. (Série Estudos Rurais).

AQUINO, J. R.; et al. Dimensão e características do público potencial do Grupo B do PRONAF na região Nordeste e no estado de Minas Gerais. In: SCHNEIDER, S.; FERREIRA, B.; ALVES, F. (Orgs.). Aspectos multidimensionais da agricultura brasileira: diferentes visões do censo agropecuário 2006. Brasília: IPEA, 2014. p. 77-105.

AQUINO, J. R.; GAZOLLA, M.; SCHNEIDER, S. Um retrato do lado pobre da agricultura familiar no Estado do Rio Grande do Sul. 53 Congresso da Sociedade Brasileira de Economia, Administração e Sociologia Rural. João Pessoa, 26 a 29 de julho de 2015, 20p.

BARAŃSKI, M.; et al. Higher antioxidant and lower cadmium concentrations and lower incidence of pesticide residues in organically grown crops: A systematic literature review and meta-analyses. British Journal of Nutrition, United Kingdom, Cambridge University Press, v. 112, n. 5, p. 794-811, 2014.

BLANC, J.; KLEDAL, P. R. The Brazilian organic food sector: Prospects and constraints of facilitating the inclusion of smallholders. Journal of Rural Studies. Elsevier, v. 28, n. 1, p. 142-154, 2012.

BRANCHER, P. C. As faces da certificação de produtos orgânicos no Brasil: o caso do mercado da Região Metropolitana de Curitiba-PR. XLIII Congresso da Sociedade Brasileira de Economia, Sociologia e Administração Rural. Anais... 2005, 20p.

BRASIL. Câmara dos Deputados. Lei no 11.326, de 24 de julho de 2006. Estabelece as diretrizes para a formulação da Política Nacional da Agricultura Familiar e Empreendimentos Familiares Rurais. DOU - Brasília, 2006, p. 1.

BRASIL. Câmara dos Deputados. Lei no 10.831, de 23 de dezembro de 2003. Dispõe sobre Agricultura Orgânica e dá outras providências. DOU - Brasília, 2003, Seção 1, p. 8.

BRUNORI, G.; ROSSI, A.; MALANDRIN, V. Co-produzing transition: innovation processes in farms Adhering Solidarity-based Purchase Groups (GAS) in Tuscany, Italy. International Journal of Sociedad of Agricultural and Foods. Pisa, v. 18, n. 1, p. 28-53, 2010. 
CIAPO. Plano Nacional de Agroecologia e Produção Orgânica - PLANAPO: relatório de balanço 2013-2015. Brasília, setembro/2016. 92p. Disponível em: <http://www.mda.gov.br/sitemda/sites/sitemda/files/user_arquivos_3/relatorio_de_bal anco_2013_2015.pdf>. Acesso em: 18 jan. 2017.

COMUNELLO, F. J. Produto Orgânico de Produção Agroecológica: a sensibilidade jurídica dos produtores agroecológicos. Extensão Rural, Santa Maria, v. 20, n. 1, Jan./Abr. de 2013.

DALCIN, D.; SOUZA, Â. R. L.; FREITAS, J. B.; DEWES, Â. D. P. H. Organic products in Brazil: from an ideological orientation to a market choice. British Food Journal. v. 116, issue 12, p. $1998-2015,2014$.

DEL GROSSI, M. E.; MARQUES, V. P. M. A. Agricultura familiar no censo agropecuário 2006: o marco legal e as opções para sua identificação. Estudos Sociedade e Agricultura. Rio de Janeiro, v. 18, n. 1, p. 127-157, abr./2010.

DELGADO, G. C. D. Do capital financeiro na agricultura à economia do agronegócio: mudanças cíclicas em meio século (1965-2012). Porto Alegre: Editora da UFRGS, 2012.

DIAS, V. V.; SCHULTZ, G.; SCHUSTER, M. S.; TALAMINI, E.; RÉVILLION, J. P. O mercado de alimentos orgânicos: um panorama quantitativo e qualitativo das publicações internacionais. Ambiente \& Sociedade. São Paulo, n. 1, p. 161-182, 2015.

GLIESSMAN, S. R. Agroecologia: processos ecológicos em agricultura sustentável. Porto Alegre: Editora da UFRGS, 2000. (Série Estudos Rurais).

GODFRAY, C.; et al. 'Food security: the challenge of feeding 9 billion people'. Science. v. 327, p. 812-818, 2010.

GUTHMAN, J. The trouble with 'organic lite' in California: a rejoinder to the 'conventionalisation' debate. Sociologia Ruralis. v. 44, n. 3, p. 301-316, 2004.

GUZMÁN, E. S.; WOODGATE, G. Agroecology: Foundations in Agrarian Social Thought and Sociological Theory. Agroecology and Sustainable Food Systems. v. 37, issue 1, p. 32-44, 2013.

IAASTD. Agriculture at a crossroads. International Assessment of Agricultural Knowledge, Science and Technology for Development, Island Press, Washington, DC. 2009.

IBGE. Censo agropecuário 2006. Brasil, Grandes Regiões e Unidades da Federação. Primeiros Resultados. Disponível em: < http://biblioteca.ibge.gov.br/visualizacao/periodicos/51/agro_2006.pdf >. Acesso em: 20 mar. 2017.

Agricultura Familiar. Primeiros resultados. Brasil, Grandes Regiões e Unidades da Federação. Censo agropecuário 2006. Brasília/Rio de Janeiro: MDA/MPOG, 2009. 
IFOAM. Growth continues: $\mathbf{4 3 . 7}$ million hectares of organic agricultural land worldwide. Disponível em: < http://www.ifoam.bio/sites/default/files/press-releaseworld-2016-english.pdf >. Acesso em: 18 mar. 2016.

INTERNATIONAL PANEL OF EXPERTS ON SUSTAINABLE FOOD SYSTEMS (IPES-FOOD). From uniformity to diversity: a paradigm shift from industrial agriculture to diversified agroecological systems. Disponível em: < http://www.ipesfood.org/images/Reports/UniformityToDiversity_FullReport.pdf>. Acesso em: 19 mar. 2017.

KOESLING, M.; et al. Farmers' reasons for deregistering from organic farming. Organic Agricultural, v. 2, n. 2, p. 103-116, 2012.

LAGO, A.; LENGLER, L.; CORONEL, D. A.; SILVA, T. N. Agricultura familiar de produtos orgânicos: um olhar sob a ótica do marketing. Extensão Rural, Santa Maria, Ano XIII, Jan./Dez.2006.

MELÃO, I. B. Desenvolvimento rural sustentável a partir da agroecologia e da agricultura orgânica: o caso do Paraná. Nota Técnica IPARDES. Instituto Paranaense de Desenvolvimento Econômico e Social (IPARDES): Curitiba, 2010.

NIEDERLE, P. A.; ALMEIDA, L. A nova arquitetura dos mercados para produtos orgânicos: o debate da convencionalização. In: NIEDERLE, P. A.; ALMEIDA, L.; VEZZANI, F. M. (Orgs.). Agroecologia: práticas, mercados e políticas para uma nova agricultura. Curitiba: Kairós. 2013, 393p.

OLIVEIRA, D.; GAZOLLA, M.; SCHNEIDER, S. Produzindo novidades na agricultura familiar: agregação de valor e agroecologia para o desenvolvimento rural. Cadernos de Ciência \& Tecnologia. Brasília, v. 28, n. 1, p. 17 - 49, 2011.

OLIVEIRA, E. C. L. O Plano Nacional de Agroecologia e Produção Orgânica: resposta a um novo paradigma de Desenvolvimento Rural para o Brasil. In: Congresso Brasileiro de Economia, Administração e Sociologia Rural, 54. 2016, Maceió/AL. Anais... Maceió/AL: SOBER, 2016. 14p. (Online).

PETERSEN, P.; MUSSOI, E. M.; DAL SOGLIO, F. Institutionalization of the Agroecological Approach in Brazil: Advances and Challenges. Agroecology and Sustainable Food Systems. v. 37, n.1, p. 103-114. 2013.

PICOLOTTO, E. L. Reconhecimento da agricultura familiar e as disputas pela classe média rural. Revista Espaço Acadêmico. [S.I.], Ano XI, n. 128, p. 158-167, 2012.

PLOEG, J. D. V. Camponeses e impérios alimentares: lutas por autonomia e sustentabilidade na era da globalização. Porto Alegre: Editora da UFRGS, 2008. 372 p. (Série Estudos Rurais).

PONISIO, L. C.; M'GONIGLE, L. K.; MACE, K. C.; PALOMINO, J.; DE VALPINE, P.; KREMEN, C. Diversification practices reduce organic to conventional yield gap. Proceedings of the Royal Society. v. 282, issue 1799, 2015.

PRETTY, J. Agri-Culture: reconnecting people, land and nature. London: Earthscan, 2002. 
REDCLIFT, M.; GOODMAN, D. The machinery of hunger: the crisis of Latin America food systems. In: GOODMAN, D.; REDCLIFT, M. (Eds.). Environment and development in Latin America. UK: Manchester University Press, 1991.

REGANOLD, J. P.; WACHTER, J. M. Organic agriculture in the twenty-first century. Nature Plants. v. 2, February 2016.

RENTING, H.; MARSDEN, T.; BANKS, J. Understanding alternative food networks: Exploring the role of short food supply chains in rural development. Environment and Planning, Wageningen, v. 35, p. 393-411, 2003.

SAMBUICHI, R. H. R. et al. Avaliação do Plano Nacional de Agroecologia e Produção Orgânica: primeiros resultados. In: Congresso Brasileiro de Economia, Administração e Sociologia Rural, 54, 2016, Maceió/AL. Anais... Maceió/AL: SOBER, 2016. 9p. (Online).

SCALCO, A. R.; SERVI, R. G. Manutenção da certificação orgânica em produtores rurais. Revista em Agronegócios e Meio Ambiente. v. 7, n. 3, p. 515-534, 2014.

SCHNEIDER, S.; FERREIRA, B.; ALVES, F. (Org.). Aspectos multidimensionais da agricultura brasileira: diferentes visões do Censo Agropecuário 2006. Brasília: IPEA, 2014. v. 1. 392 p.

SEBRAE. Perfil de mercado: orgânicos. Estudos de Inteligência de Mercado. São Paulo: 2010.

SLATER, N. Real food. London: Fourth Estate, 2014.

WILLER, H.; KILCHER, L. (Eds.). The world of organic agriculture - statistics and emerging trends 2014. Switzerland: FiBL, 2014. 